\title{
La energía nuclear, una alternativa de sustentabilidad para resolver la demanda eléctrica en México. (Primera parte)
}

\author{
S.D. Bazán-Perkins \\ División de Estudios de Posgrado \\ F acultad de Ingeniería \\ E-mail: bazanperkins@hotmail.com
}

(recibido: enero de 2004; aceptado: diciembre de 2004)

\section{Resumen}

\begin{abstract}
En la actualidad es importante plantear un cambio en la política energética de México. Ante los nuevos escenarios energéticos no es viable continuar con la generación de energía eléctrica basándose en el consumo de los combustibles fósiles, como actualmente está programada. Hacia finales de la primera década del siglo XXI, las posibilidades de generación masiva de electricidad con reservas domesticas de gas, petróleo y carbón, serán casi nulas. Adicionalmente, las erogaciones hacia los sistemas de generación eléctrica con equipos obsoletos, implican gastos onerosos que frenan el crecimiento del país. La política energética de México, orientada a intensificar la generación de electricidad basándose en el gas natural y carbón mineral de importación, propicia la dependencia energética externa y fuga de divisas. En este sentido, la energía nuclear en conjunto con las fuentes de energía renovables, podrían sustentar la autonomía energética nacional al ser más rentable, además de propiciar otros beneficios como la conservación ambiental. El objetivo principal de este trabajo es proponer la diversificación en el consumo de energéticos del país con nuevas fuentes de abastecimiento basadas en la energía nuclear, así como fuentes renovables como la producción del hidrógeno para resolver la demanda de energía eléctrica que se necesita en las próximas décadas.
\end{abstract}

Descriptores: Electricidad, sustentable, hidrocarburos, gas natural, petróleo, carbón mineral, uranio, nuclear, renovable, eólica, hídrica, hidrógeno.

\section{Abstract}

A major change in the energy policies in Mexio has becoming necessany. Because the consumption of fost fuels is expensive and not renewable, new energy settings are indispensable forelectriaty generation. At the end of 21 st century first decade, there are few passibilities of massive electricity generation coming from domestic reserves of gas, petroleum and aual. Additionally, the outdated ssstems of electric energy generation have high operating costs that reduce the growth of the country. The Mexican energy policies are oriented to intensify the electriaty generation based on natural gas and mineral wa[ impontation. It produces extemal energy dependence and a leak of aurencies. In this sense, nuclear energy jointly with the renewable energy sources could support the nacional energy autonomy because is most prof Cable, furthermore to promote other benefits as the envirommental consenation. The aim of this paper is to pro pae the diversification in the energy consumption of Mexico using new sources of nuclear energy and the renewable sources of energy as hydrogen production, to resolve the demand of electric energy that is required in the next decades.

Keywords E ledriaity, sustainable, hydrocarbons, natural gas, petroleum, mineral coal, uranium, nuderr, renewable, aeolian, water, biomass, geothermal, hydrogen. 


\section{Introducción}

Esta exposición presenta un análisis retrospectivo de los servicios y fuentes energéticas aprovechables en beneficio del hombre. Para este propósito, se consultaron diversas aportaciones científicas, informes técnicos, así como de comunicación personal relacionados con el tema, siguiendo la metodología de confrontación de datos de la experiencia mundial.

La experiencia del autor, también contribuyó para realizar el análisis propuesto, sin pretender que sea exhaustivo ni determinante en su evaluación, sino más bien congruente para su divulgación. Los planteamientos sobre las fuentes de energía discutidas para México, en particular la nucleoeléctrica, representan la posibilidad para su implementación y desarrollo como una propuesta concreta.

El concepto de desarrollo sostenible surgió a finales de los 80's, en el informe Brundtland, como "un desarrollo que satisface las necesidades del presente sin comprometer la capacidad de las generaciones futuras para atender sus propias necesidades" (Brundtland, 1987). En un sentido amplio, interrelaciona los aspectos económicos, sociales y ecológicos, abogando por la ética de protección al ambiente y sus recursos naturales para la realización de los seres humanos.

En consecuencia, esta nota centra su atención en una generación eléctrica sustentable para México, haciendo hincapié en la seguridad de suministro y al menor costo, mediante tecnologias limpias que propicien el mayor progreso económico y social en un marco de alta competitividad comercial.

Al fomentar el desarrollo de las tecnologías de generación eléctrica más avanzadas, se propicia mayor riqueza y fuerza de trabajo capacitada con niveles educativos superiores y mejores condiciones de vida. En contraste, a medida en que se emplean fuentes de generación que requieren mayor empleo de la energía humana, se decrementa la productividad y calidad de vida (Bardwell, 1981).

\section{Perspectivas energéticas}

La electricidad es el principal insumo para el crecimiento económico de las sociedades actuales al permitir la producción de alimentos, medicinas, abrigo, sistemas de comunicación, el sostén del comercio y la industria. La estructura económica del país se apoya en el sector eléctrico y determina un factor esencial en las condiciones de vida actual.

México es afortunado en contar con amplia gama de recursos energéticos, como son: petróleo, carbón mineral, gas natural, uranio y la energía renovable comprendida por la hídrica, eólica, solar, geotérmica y biomasa, principalmente. Representan un conjunto de opciones de desarrollo tecnológico y de mercado. Su diversificación permite su reemplazo ante imponderables eventuales, evitando crisis energéticas y económicas.

La viabilidad del Sistema Eléctrico Nacional requiere de la incorporación continua de innovaciones tecnológicas adaptables a las condiciones y necesidades del país. Su nivel de competitividad comercial debe considerar las tendencias de los mercados de energéticos y las políticas globales sobre su desarrollo, proyectadas a corto, mediano y largo plazo. Se. persigue que estas condiciones cubran en forma eficiente la demanda de electricidad al menor costo y generen la mayor prosperidad social $y$ ambiental.

La estrecha afinidad con la evolución logística mundial de los energéticos, incluyendo los cambios tecnológicos de mercados y políticas de empleo, no quiere decir que los proyectos energéticos de México se deban ajustar a un programa global definido. Aunque conviene, tal condición no es absolutamente esencial. De hecho, existen casos de nuevas líneas de desarrollo tecnológico que aún no están muy difundidas para el mejor aprovechamiento de los recursos energéticos y que cubren con mejor calidad la demanda de electricidad. También, se puede acudir a nuevas fuentes de energía para ser incorporadas por primera vez.

Se advierte que en la próxima década, no existe un plan para incorporar al Sistema Eléctrico Nacional nuevas instalaciones para aprovechar la energía nuclear. Tampoco se involucra al hidrógeno dentro de la planeación energética del país, según la Prospectiva del Sector Eléctrico 2002-2011 y otros programas (Fernández, 2003). En cuanto a la energía eólica, su crecimiento será mínimo, al pasar de 3 MW a 104 MW (SENER, 2003). En todas 
estas alternativas, los argumentos principales serían los altos costos de su generación, en comparación con el consumo de las supuestas y enormes reservas domésticas de gas $\mathrm{y}$ petróleo que ya no responden a las expectativas planteadas para la generación eléctrica por medio de los hidrocarburos. Por el contrario, los argumentos expuestos determinan que la energía nuclear, conjuntamente con la renovable, implican una alternativa barata, viable y única para resolver la demanda energética que se espera en las próximas décadas.

\section{Tendencias del mercado y avances tecnológicos en la generación de electricidad de principios del Siglo XXI}

Desde principios del siglo XXI resaltan las innovaciones tecnológicas y profundos cambios en el escenario del mercado de los energéticos, esto impulsa el empleo de las fuentes de generación renovables, nuclear y el hidrógeno. En otros casos, existe oposición por las tecnologías de generación eléctrica que deterioran el ambiente y la salud humana. Entre las más contaminantes por sus efectos globales, están los combustibles fósiles (carbón mineral, petróleo y gas) que al quemarse producen gases de efecto invernadero. También se ha advertido que no todas las fuentes de energía renovable son sustentables y de mercados de "energía verde", como ocurre con las grandes hidroeléctricas y la eólica, cuando se emplea en forma intensiva (Tabla 1).

En gas natural, desde los 80's promueve su uso intensivo a nivel global para la generación de electricidad, mediante el sistema de ciclo combinado, por sus ventajas tecnológicas, económicas y

Tabla 1. Niveles de afectaciones de las tecnologias de generación eléctrica al ambiente y a la salud humana (por Terajulio) | Elaboración propia con datos de APPA, 2002|

\begin{tabular}{ccccc}
\hline $\begin{array}{c}\text { Tecnología de } \\
\text { generación }\end{array}$ & Calentamiento global & $\begin{array}{c}\text { Disminución de la } \\
\text { capa de ozono }\end{array}$ & $\begin{array}{c}\text { Sustancias } \\
\text { carcinógenas }\end{array}$ & Acidificación \\
\hline Carbón mineral & $55 \%$ & $3 \%$ & $13 \%$ & $48 \%$ \\
Petróleo & $22 \%$ & $86 \%$ & $83 \%$ & $47 \%$ \\
Gas natural & $22 \%$ & $1 \%$ & $3 \%$ & $5 \%$ \\
Mirihidráulica & $0 \%$ & $0 \%$ & $0 \%$ & $0 \%$ \\
Eólica & $1 \%$ & $3 \%$ & $1 \%$ & $0 \%$ \\
Nuclear & $0 \%$ & $7 \%$ & $0 \%$ & $0 \%$ \\
\hline
\end{tabular}

ambientales. Sin embargo, el acelerado crecimiento de su demanda es negativa en los países que no cuentan con reservas suficientes, capacidad de producción, almacenamiento, transporte y suministros del exterior. El efecto inmediato es el desabasto del energético, volatilidad e incrementos de su precio, desequilibrios de mercados e inviabilidad para la generación de electricidad. Estas situaciones obligaron a modificar su política energética como aconteció en los Estados Unidos.

\section{La economia de la energía eólica}

Desde principios del siglo XXI, la energía eólica destaca como la mayor promesa de las energías renovables para producir electricidad en forma abundante a bajo precio y a corto plazo. Su desarrollo explosivo se debe al aplicar nuevas tecnologias y a la promoción del mercado mediante subsidios de los gobiernos, en este sentido, los principales líderes son Alemania, España y Estados Unidos (Gutín, 2001 y 2002).

$\mathrm{El}$ crecimiento acelerado de la industria eoloeléctrica se refleja en sus estadísticas, por su mayor competitividad; en el 2001 la producción mundial alcanzó los 24,313 MW de capacidad instalada, y en el 2002, fue aún mayor de 30,379 MW, lo cual representa un incremento de 6,066 MW (24.94\%) en un año (Eurobser, 2003). Superior en tres veces al crecimiento de la industria nucleoeléctrica, de 1,748 MW en el 2000. Así por ejemplo, de 1995 a 2001 la generación eoloeléctrica crece $487 \%$ y en el mismo período el empleo de las carboeléctricas decrece 9\% (REW, 2002a). 
Durante el 2002, la Unión Europea alcanzó una capacidad de 22,331 MW, un $30.4 \%$ más que el año anterior. En la India se alcanzó 1,702 MW, es decir, $12.90 \%$ más que en 2001. En los Estados Unidos se cuenta con una capacidad de 4,708 MW, la cual es $10.90 \%$ más que en el 2001 (Eurobser, 2003), obteniendo un costo promedio de generación de $2.5 \mathrm{CUS} / \mathrm{kWh}$ (REW, 2002b).

En el mercado mundial de aerogeneradores, alcanza un alto volumen de ventas las de $600 \mathrm{~kW}$, seguidas de los de $750 \mathrm{~kW}$ hasta el $1.5 \mathrm{MW}$, y los de $50 \mathrm{~kW}$ que cada vez son más ligeras y económicas (Ruiz y Garre, 2000). Los generadores de gran capacidad entre 1 y 2 MW, (clase megavatio), son viables en lugares con grandes espacios y vientos estables. En Alemania se están incorporando los aerogeneradores de 3.5 MW (dewind 9), donde hacia el 2006 se dará un salto a los de 5 MW (Infoenergía 2001 a y 2002b).

En México, al 2002, la capacidad instalada es de apenas 3 MW, equivalentes a dos aerogeneradores de clase megavatio de 1.5 MW. Hasta el 2006, entrará en operación la Central Eólica La Venta II (Oaxaca), de 101 MW y un costo estimado de $3.0 \mathrm{CUS} / \mathrm{kWh}$, en una región que cuenta con un potencial para 3000 MW (SENER 2003).

Por tanto, y debido a su éxito, en varios países se está intensificando el desarrollo de parques de aerogeneradores implicando incentivos de mercado con programas nacionales; sobre todo, porque a corto plazo es posible elevar el potencial de generación de electricidad que difícilmente se logra con otras tecnologias. Los avances tecnológicos incrementan el aprovechamiento de las regiones favorables al cubrir su potencial con menor número de aerogeneradores de mayor capacidad y menor costo de generación.

\section{La economia de la energia nuclear}

La industria nucleoeléctrica desde sus inicios, de 1954-56 y durante unas tres décadas, mantuvo un desarrollo y crecimiento sostenido; sin embargo, a partir de 1986, tuvo un serio revés por causa del accidente de Chernobyl, que llevó a frenar totalmente su crecimiento en Europa Occidental y en Estados Unidos, incluyendo el cierre de centrales en ciertos países como Italia. Entre tanto, su expansión cobró gran impulso en los países asiáticos y de la cuenca del Pacífico Oriental, como Japón, Corea, China, Taiwán, India; así como de Europa Oriental, como Rusia, Ucrania, Bulgaria y Eslovaquia (CNEA, 2002).

Al inicio del siglo XXI, se presenta un progresivo proceso de revalorización del potencial de la energía nuclear, en donde nuevos países se han sumado para implementar sus bases de desarrollo. Los factores técnicos y económicos que la impulsan son: a) Inestabilidad ante el alza de los precios de los hidrocarburos en general; y en particular, del gas natural en los Estados Unidos, Brasil y Argentina; b) Impactos negativos al medio ambiente por los gases de efecto invernadero (principalmente $\mathrm{CO} 2$ ) por la quema de combustibles fósiles (Tabla 1); c) $\mathrm{El}$ incremento de la demanda de electricidad por encima del crecimiento de la economía (PIB), en la gran mayoría de los países; d) El creciente interés y compra de centrales nucleares en operación por empresas privadas; e) Avances tecnológicos, mejoramiento en su operación y administración que propician elevar su factor de planta (Figura 1); f) El decremento acelerado de los costos de generación de las nuevas nucleoeléctricas y h) Las iniciativas del congreso de los Estados Unidos para reiniciar la construcción de plantas nucleares de 111 generación avanzadas a corto plazo y IV generación a mediano plazo.

Las actuales tecnologias de fisión nuclear de III generación son resultado de los trabajos de investigación por compañías privadas, institutos de investigación, universidades y gobiernos. En algunos casos, se trabaja sobre tecnologias similares en versiones diferentes o en proyectos integrados por varios países. Todas estas innovaciones se proyectan en seis características: 1) Mecanismos de alta seguridad y bajo riesgo de accidentes; 2) Competitividad económica por su menor inversión en la construcción, operación, mantenimiento y aumento de vida operativa a 60 años; 3) Empleo de materiales más resistentes, seguros y con transportación; 4) Alta seguridad en el manejo de combustibles y sus desechos; 5) Mayor eficiencia del reciclamiento de combustibles; 6) Incremento de la eficiencia de las plantas (IAEA, 2002; WNA, 2003).

Hacia el 2010, iniciarán su construcción diversos modelos de reactores de III generación avanzados (Generación 111 +). Dentro de los más acogidos en el mercado Europeo está el reactor EPR (European Pressurized Water Reactor) de 1750 MW, 
desarrollado por Francia y Alemania para actualizar sus plantas nucleoeléctricas (FRAMATOME-ANP, 2003). En los Estados Unidos, hacia el 2012, estarán en construcción unos 30 reactores, el de mayor demanda es el Westinghouse AP 1000 de 1100 MW con un costo de generación de $3.5 \mathrm{CUS} / \mathrm{kWh}$. En Sur África se contempla construir hacia el 2010, de 10 a 14 plantas del Pebble Bed Modular Reactor (PBMR) cada una de 165 MW con costos de generación de $1.6 \mathrm{CUS} / \mathrm{kWh}$. Los costos de inversión son del orden de 10001400 \$US/kW instalado (NEI, 2003 c; WNA, 2003).

En cuanto a las reservas mundiales de uranio convencional probadas, se estiman en categorias por el costo del concentrado, de $\leq 80$ \$US/Kg de $\mathrm{U}_{3} \mathrm{O}_{8}$ se tienen $3,107,000.0$ toneladas y de $\leq 130$ \$US/Kg de U308 se cuenta con 3,933,000 t, distribuidas geográficamente en los cinco continentes. En el 2000, la producción fue de 36,112 t y la demanda de los 438 reactores nucleares comerciales fue de 64,0 $14 \mathrm{t}$, la diferencia de 27,902 t se cubre de las reservas obtenidas del desarme nuclear. Para el caso de México, en las estadísticas mundiales se aprecia que desde hace más de una década no figura entre los 38 países que reportan inversión en la exploración de yacimientos de uranio y en la adquisición de tecnología minera para su extracción. (Uranium, 2000 y 2001).

Al año 2000, existen 21 países con tecnología para producir combustibles nucleares en sus diferentes fases, que garantizan la estabilidad de su precio en el mercado (WNA, 2000). Como comenta Cohen (1983), las grandes reservas de uranio y los avances tecnológicos llevan a que se tenga suficiente combustible nuclear para cubrir las necesidades de la humanidad por largo tiempo. La energía nuclear, suponiendo que usemos reactores de neutrones rápidos, durará por varios miles de años, es decir, mientras el Sol esté en condiciones de mantener la vida en la Tierra.

\section{El programa de energía atómica 2010}

\section{de los Estados Unidos}

Hacia finales del 2001, los Estados Unidos en respuesta al cambio de los escenarios del mercado de energéticos y de los avances tecnológicos, se decide por la energía nuclear como la mejor opción, que impulsa el mayor desarrollo económico en condiciones de sustentabilidad (N EI, 2002c).

Su Programa de Energía Atómica 2010 es un plan energético al 2030. Contempla la entrada en operación comercial a gran escala de los reactores nucleares avanzados de III generación (Gen. III+) y de IV generación. Se considera del 2010 al 2020 el ingreso a operación comercial de unos 50 reactores nucleares de generación III +; de 1000 MW ó su equivalente para cubrir 50,000 MW enfriados por agua ligera o vapor, adicionales a los 12,000 MW que se espera incrementar con las actuales plantas. Del año 2015 al 2025, la entrada

Se comparan con la pianta nuclear de Laguna Verde en México de 2000 al 2003 [Elaboración prpia con datos de IAEA, 2002 y 2003; SENER, 2002 y 2003]

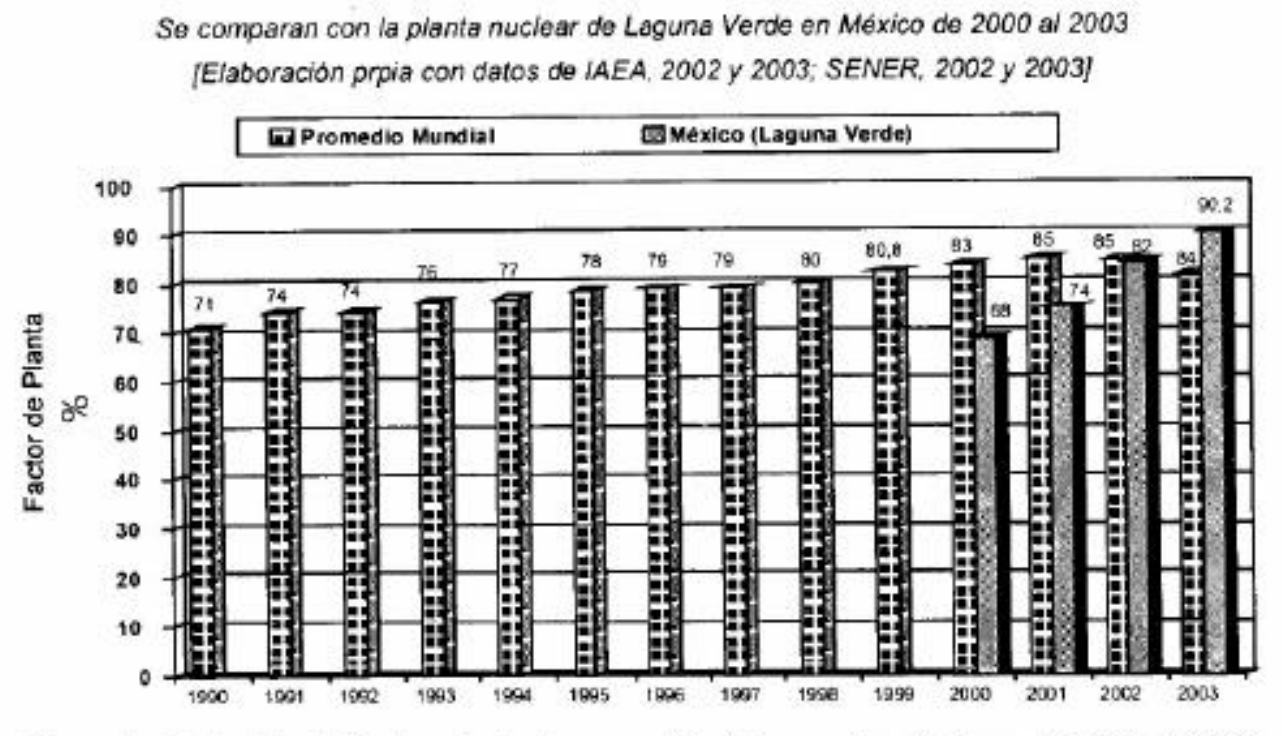

Figura 1. Evolución del factor de planta promedio de las nucleoeléctricas de 1990 al 2003 comercial 
de reactores nucleares de IV generación que incluye modelos para producir hidrógeno a partir del agua. Finalmente, antes del 2030 se pretende garantizar un minimo volumen de combustibles nucleares gastados y un menor tiempo de duración, como emisores peligrosos (U.S. Govemment, 2003; NEI, 2003a y 2003 b).

Para el desarrollo de los reactores de IV generación se adicionaron varios países que cuentan con tecnologias del ciclo de combustible nuclear, por ser la principal línea de investigación del programa. En julio de 2001, Argentina, Brasil, Canadá, Francia, Japón, Corea del Sur, Sudáfrica, Reino Unido y Estados Unidos, firmaron una carta formal para identificar y desarrollar tecnologías de la IV generación sobre una base multilateral (U.S. Government, 2003).

Por parte de América Latina participan Argentina y Brasil, que cuentan con desarrollo tecnológico avanzado en el campo industrial de explotación, producción, enriquecimiento, recon versión y tratamiento de combustible nuclear, con los que han obtenido sus propias patentes y la participación internacional. En este aspecto, México desde 1984, no cuenta con la infraestructura, experiencia, personal técnico y científico especializado en la industria del ciclo de combustibles nucleares; desde que decidió liquidar a su personal con el cierre de Uranio Mexicano (URAMEX). De esta forma,
México se excluyó de un campo de desarrollo tecnológico y científico que incluye todas las ramas de desarrollo profesional, desaprovechando las oportunidades del mercado; asimismo, debilitó sus posibilidades para participar en proyectos internacionales y de licitación de producción de combustibles nucleares para las nuevas tecnologias de reactores nucleares, por lo menos al nivel de Yelow Cake, que es la materia básica.

\section{La economía de la energía del hidrógeno}

El hidrógeno es el elemento más abundante del universo, el cual en estado natural elemental no existe formando depósitos en la Tierra. La tecnologia comercial para la producción limpia del hidrógeno se espera obtener a corto y mediano plazo, empleando principalmente la energía nuclear y renovable; ya que la actual forma de producirlo, a partir de combustibles fósiles, resulta costosa y contaminante (Figura 2). A largo plazo, será una fuente de energía relevante en la generación de electricidad en diferentes escalas y principal sustituto de los combustibles del parque vehicular a base de hidrocarburos. En países como Alemania, Francia, Islandia, Estados Unidos, España, Inglaterra y Japón, entre otros más, ya cuentan con las primeras estaciones de despacho para que el hidrógeno sea empleado como combustible para el parque vehicular.

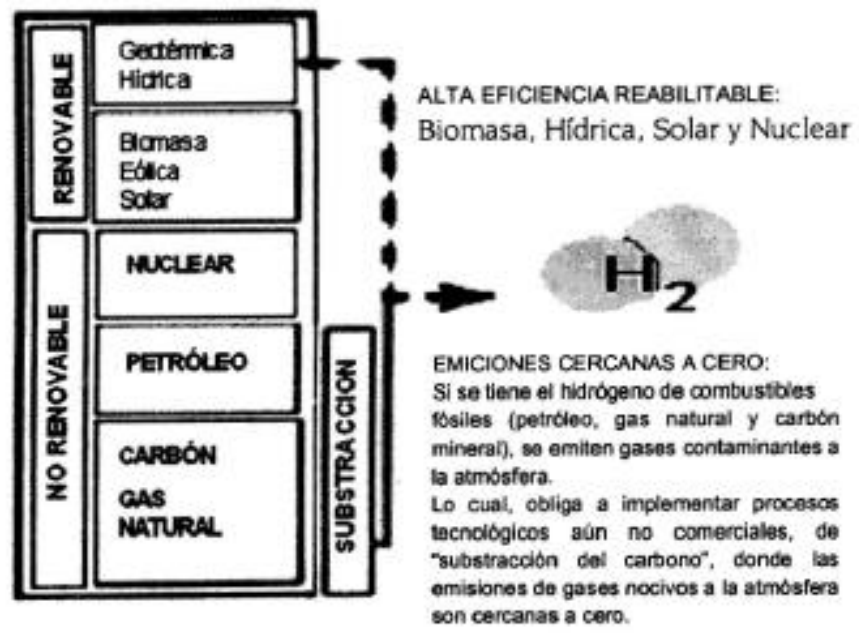

Figura 2. Diagrama de fuentes de energía para producir hidrógeno (Adaptado de DOE, 2002a) 


\section{S.D. Bazán-Perkins}

Como fuente de desarrollo energético de una nación, el hidrógeno está en proceso para pasar a una realidad. En los Estados Unidos está en marcha el programa que lo llevará de una economía del petróleo a una economía del hidrógeno, en un horizonte de planeación de 40 años (Figura 3). Las bases de este programa se describen en la conferencia "National Hydrogen Vision Meeting" de noviembre del 2001.

En el 2003, los gobiernos de Brasil, Canadá, Australia, China, Alemania, Japón, Corea, Noruega, India, Italia, Francia, Islandia, Reino Unido y Estados Unidos crearon el IPHE (International Partnership for the Hydrogen Economy) como mecanismo de colaboración internacional para investigar, incorporar, desarrollar y financiar la producción $y$ empleo del hidrógeno en sus economías (IPHE, 2003).

La economía del hidrógeno se determina en el concepto de fabricación artificial. La materia esencial comúnmente empleada es el gas natural, que además obtiene como subproducto $\mathrm{CO}_{2}$ que afecta el ambiente. El hidrógeno se puede obtener en forma limpia a partir de la biomasa por pirolisis, y del agua mediante electrólisis o por procesos termoquímicos.

Hacia el 2015, se contará en el mercado con la tecnología para la producción del hidrógeno a gran escala, con costos bajos $\mathrm{y}$ en forma limpia a partir del agua $\mathrm{y}$ mediante procesos termoquímicos, em- pleando la energía de los reactores nucleares de III + y IV generación de alta temperatura $\left(900^{\circ}\right.$ C). En este proceso, el hidrógeno se separa del agua por cracking, por etapas, empleando azufre-yodo ( $\mathrm{NE}, 2003) . \mathrm{El}$ costo de generación de electricidad empleando el hidrógeno en las celdas de combustible, de 2 C US/kWh, es ya competitivo con la tecnologia del gas natural por ciclo combinado, al igual que su eficiencia, procesos de producción y empleo práctico (DOE, 2002a).

\section{Fuentes de generación actual}

Las reservas de petróleo en el mundo

Es oportuno hacer un compendio de las materias energéticas mundiales para su aprovechamiento en la generación de electricidad, como es el petróleo, gas natural, carbón mineral y uranio. Básicamente, dependiendo de su duración y tecnologías disponibles se podrá planificar su horizonte de empleo mediante importaciones a través del comercio mundial, aunadas a las reservas domésticas de México; entonces, la pregunta básica sería ¿para cuánto tiempo se tienen a disposición las reservas convencionales de estos energéticos en el mercado global?

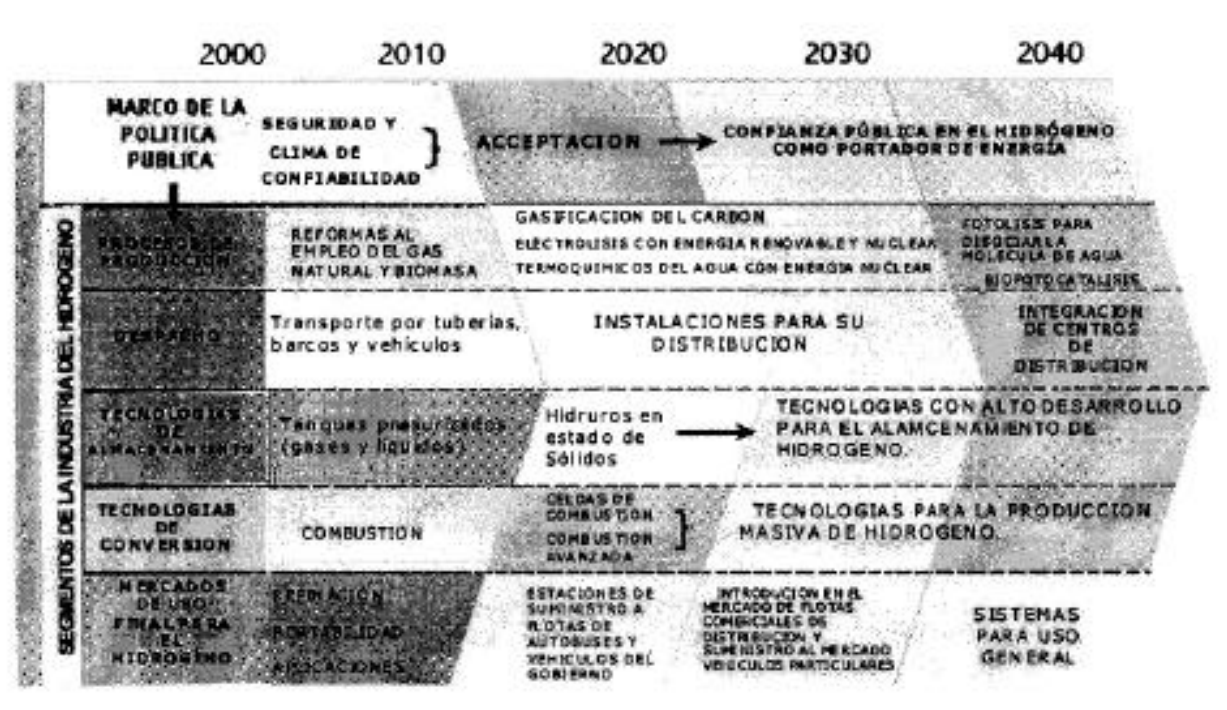

Figura 3. Programa para la transición a la economía del hidrógeno en Estados Unidos, 2000-2040 (Adaptada de DOE, 2002a) 
Según BP (2003), expone que el total de reservas de petróleo probadas convencionales en el mundo son de 104.7 mil millones de barriles, en donde la relación de reservas/producción alcanza para 40.6 años. Así representa el limite en que se podrá contar en el mercado internacional con petróleo de menor costo de extracción. Considerando lo anterior, el plan de los Estados Unidos es pasar a una economía del hidrógeno hacia el 2040 (Figura 3).

Sin embargo, Laherrere (2003) ha establecido otros factores adicionales tomados de la base de datos de las principales empresas petroleras, como son el efecto de los nuevos desarrollos tecnológicos, ajustes de reservas 5 años después de su descubrimiento y la capacidad de producción de los campos. En suma, define el agotamiento de las reservas de petróleo crudo convencionales hacia el 2030, y las de gas natural en el 2050.

De hecho, el empleo del petróleo crudo en un país industrializado para generar en forma masiva electricidad, resulta un desperdicio económico, porque representa un alto costo. El petróleo tiene un valor agregado mayor en otros sectores económicos, por ello, en el mundo el consumo de petróleo crudo para generar electricidad ha decrecido, ya que en el 2001 era de un $8 \%$
(IEA, 2002), en los Estados Unidos de un $3 \%$, que proyecta al 2020, menos de $1 \%$ (U.S. Government, 2001), actualmente en los países de la Comunidad Europea es de apenas 9\% (Figura 4).

En México, los derivados del petróleo están entre las principales fuentes de generación de electricidad. De acuerdo con la $\mathrm{CFE}$ (2002), al año 2000, el $46.7 \%$ de la generación de electricidad se obtuvo del combustóleo y aceite diésel, no obstante, existe un plan en proceso para que hacia el 2010 sea el gas natural la principal fuente de generación, con un 54\% (Figura 5).

Ante el agotamiento de las reservas mundiales de petróleo convencional hacia el 2030 y los altos precios del gas natural en el mercado, la alternativa para México sería orientar sus esfuerzos hacia una economía del hidrógeno, empleando fuentes de energía renovables y nuclear con tecnologías III+ y IV generación, obtenido del agua y la biomasa. Los argumentos para esta propuesta se describirán en la segunda parte de este artículo, al considerar que las reservas domésticas probadas de hidrocarburos son bajas, las del carbón mineral son de mala calidad y se cuenta con alto potencial de reservas uraniferas que podrian ser convertibles en reservas probadas a corto plazo.

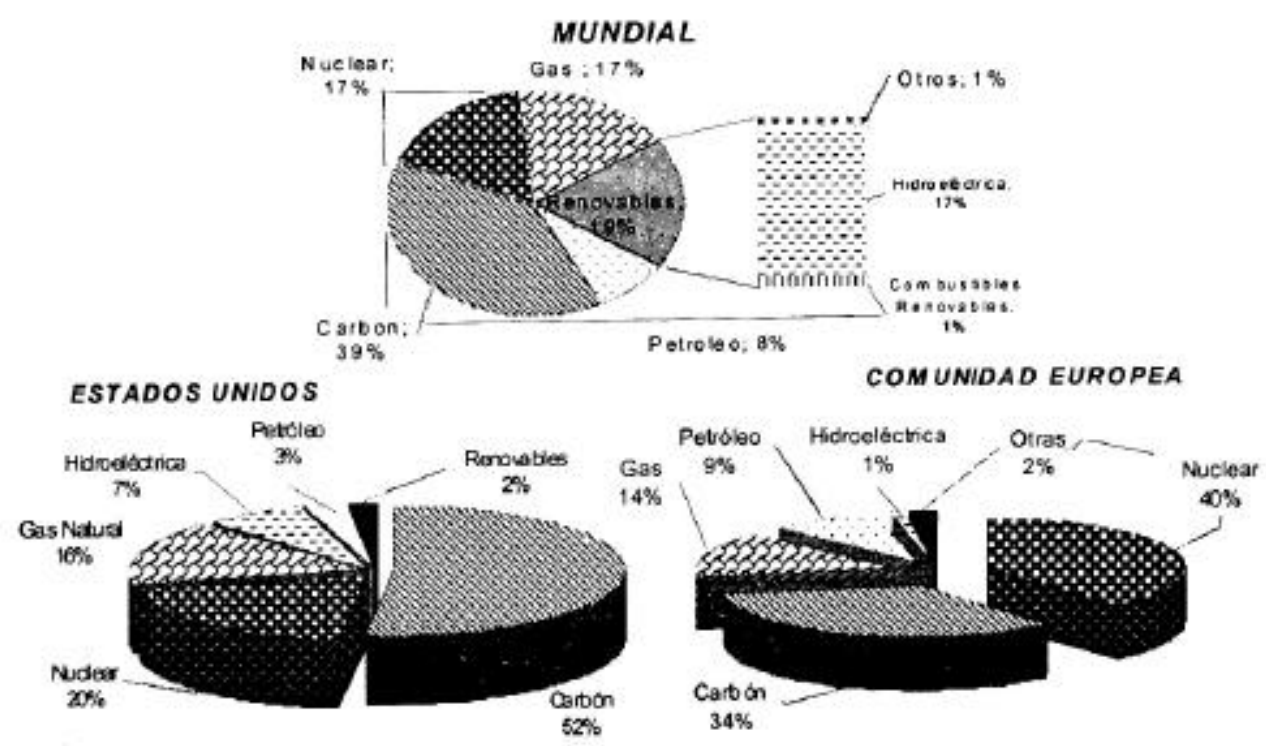

Figura 4. Empleo de las fuentes de electricidad a nivel mundial, Estados Unidos y la comunidad europea en el 2000 (Elaboración propia con datos de US, Government, 2001; IEA 2001 y 2002) 


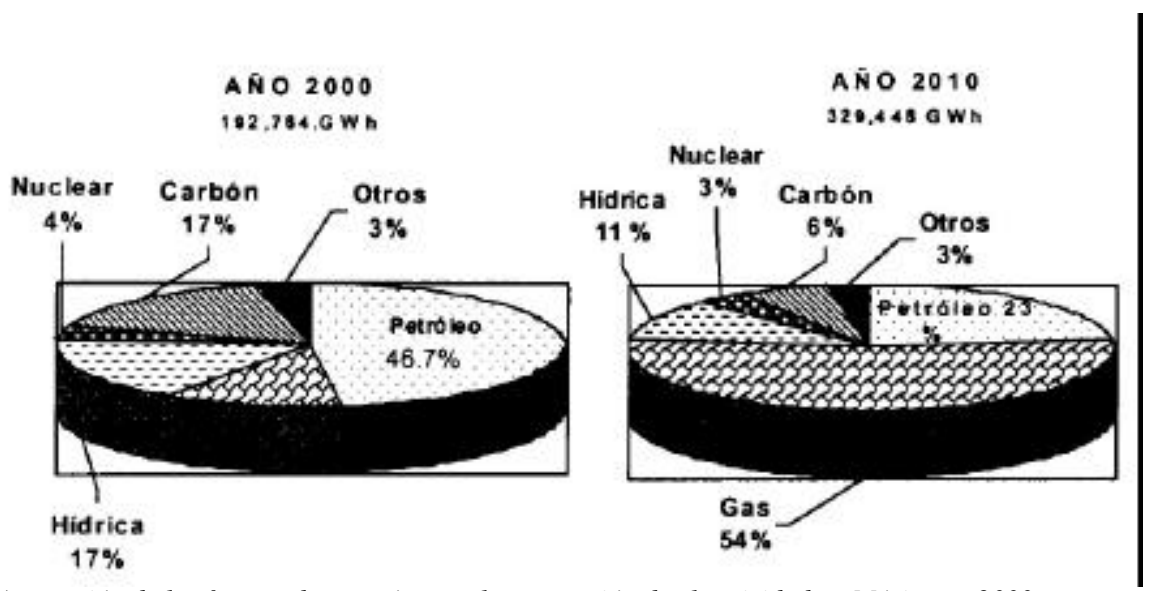

Figura 5. Aportación de las fuentes de energía para la generación de electricidad en México en 2000 y su proyección al 2010 (Adaptado de SENER, 2001)

Existen pues, varias razones para no emplear los derivados del petróleo crudo como principal fuente de generación de electricidad y la producción de hidrógeno, como sus graves afectaciones al ambiente y a la salud. Esto es, que no obstante de un empleo mundial bajo (8\%) en la producción de flujo eléctrico, sus consecuencias negativas son impactantes. Produce el $22 \%$ de los gases de efecto invernadero, afecta en el decremento de la capa de ozono en un 86\%, genera el $47 \%$ en la acidificación de la atmósfera, hidrosfera y suelos. Es el principal responsable, en 83\%, de la formación de sustancias carcinógenos que provocan cáncer y aumenta la mortandad (APPA, 2002), (Tabla 1).

\section{Las reservas de gas natural en el mundo}

En cuanto al gas natural, para el 2002, las reservas mundiales eran de 5501.5 trillones de pies cúbicos (Tpc) y alcanzaban para 60.7 años. En América del Norte, los Estados Unidos cuenta con 183.5 Tpc para 9.6 años y con el 3.3\% de las reservas mundiales. Canadá cuenta con 60.1 Tpc para 9.3 años y $1.1 \%$ de las mundiales; y México tiene 8.8 Tpc para 7.1 años que representan el $0.2 \%$ de las reservas del mundo (BP, 2003).

\section{La politica energética de Estados Unidos en cuanto al gas natural}

En junio de 2003, Greenspan el Presidente de la Reserva General de Estados Unidos Greenspan (2003a y b), expuso ante el Senado la problemática del mercado del gas natural y sus efectos negativos en la economía de este país. En principio, reconoce que en los 90's se contaba con bajos precios del gas, lo cual ayudó a impulsar la economía de los Estados Unidos, en particular, a las industrias de acero, vidrio, química $\mathrm{y}$ fertilizantes, por lo que muchos transformaron sus plantas para un mayor consumo del combustible. Pero hacia el inicio del presente siglo, la demanda ha superado a la capacidad de oferta y su precio va en ascenso. El precio del combustible es alto, en promedio, al primer trimestre del 2003 es de 5.91 \$US/millón de Btu, en los Estados Unidos. Ante esta situación, señala que: "Si permanecemos en estos niveles muy elevados (precio), nosotros veremos alguna erosión en variables macroeconómicas," y el problema no se puede resolver a corto plazo. De tal forma que en el futuro, el energético no volverá a ser un combustible barato.

Evidentemente, la excesiva promoción de empleo del gas natural en los Estados Unidos para la generación de electricidad, llevó a desequilibrios en su precio; hacia 1998, dejó de ser el más barato con respecto al mercado de gas de Francia, Alemania y España (IEA, 2002). A partir de un análisis preparado por el gobierno, se determina que con un precio del gas natural de 4.00 SUS/ millón de Btu, los inversionistas estarán generando beneficios provechosos y podrian_ continuar construyendo nuevas termoeléctricas a base de gas natural de ciclo combinado. Sin embargo, si su precio supera los 5.00 \$US /millón de Btu no recuperarían la inversión y el costo del capital, por lo que se 
recomienda cancelar la construcción de nuevas plantas termoeléctricas a base de gas natural, así como suspender las que están operando (Herman et al., 2001).

En lo que va del 2003, los precios del gas natural se sitúan por arriba de los 5.00 \$US/millón de Btu en el mercado de los Estados Unidos. Esto tiene importantes implicaciones, debido a que el 95\% de las nuevas plantas termoeléctricas que operan en este país son a base de gas, se están convirtiendo en un sector débil y en un nicho de inversión de oportunidades para ser remplazadas por otras tecnologias más rentables, como nucleoeléctricas y grandes carboeléctricas.

\section{La economía del carbón mineral en la generación de electricidad}

En la actualidad, existe una aversión mundial por continuar empleando al carbón mineral como fuente de generación de electricidad, incluso por países que cuentan con grandes reservas de éste energético. Por ello, es importante conocer las causas que motivan el decremento de su empleo, de una fuente tradicional, de bajo costo de generación, con abundantes reservas y países productores que garantizan estabilidad del precio del energético.

En efecto, la mayor parte de la energía eléctrica del mundo se genera en termoeléctricas alimentadas con carbón, al 2001 aportaron el 39\% (Figura 4). Sus reservas se estiman en 984,453 millones de toneladas, suficientes para 204 años con los actuales niveles de producción y consumo. A diferencia del petróleo, gas y uranio, los yacimientos de carbón mineral están distribuidos más equitativamente por todo el orbe. Al clasificar las reservas mundiales por regiones geoeconómicas, se advierte que tres son deficitarias en carbón. mineral, como son: Medio Este (0.2\%), América Latina (2.2\%) y África (5.8\%). En contraste, existen grandes concentraciones en Europa y Euroasia con el 36.1\%; la Ex Unión Soviética con el 23.4\%, Norte América con el 26.1\% y en Asia y Australia con el 29.7\% de las reservas mundiales. Los Estados Unidos cuenta con el 25.4\% y México menos del $0.1 \%$ (BP, 2002 y 2003).

Los Estados Unidos es el país con las reservas más grandes de carbón mineral, con fajas de cientos de kilómetros de largo, distribuidos en varias provincias como los: Apalaches, Campos Interiores y Las
Montañas Rocosas. Además, cuenta con la provincia de carbón bituminoso más extensa y de mejor calidad del mundo de $180,000 \mathrm{Km}^{2}$, siendo el $75 \%$ explotables (Dunbar, 1980; Bateman, 1982).

Desde 1998, se aprecia el decremento de la tasa de crecimiento del consumo del carbón mineral para producir electricidad (Echávarri, 2002). La razón se debe al menor desarrollo económico que propicia, así como sus efectos nocivos a la salud y al ambiente (Tabla 1). Existen aún algunos países cuya estructura energética depende en gran medida del carbón mineral para la generación de electricidad, como ocurre en Polonia y Sur África que representa el 95\%, Australia el 75\%, India y China cubre el $70 \%$, Estados Unidos el 52\% y Alemania el $51 \%$.

Por ejemplo, China posee el $11.6 \%$ de las reservas mundiales de carbón mineral que la ubican en tercer lugar, por lo que ha decidido no invertir en nuevas carboeléctricas al ser una tecnología obsoleta de bajo progreso económico, prefiriendo canalizar sus inversiones a otras tecnologías de generación más avanzadas $\mathrm{y}$ de efectos multiplicadores en su economía. En cambio, continuará promoviendo la exportación de carbón mineral por ser una fuente importante de generación de divisas extranjeras y empleos, siendo México uno de sus clientes más recientes (Diario del Pueblo, 2000, 2001 a y b).

En efecto, la tecnología de las carboeléctricas es de las más atrasadas, y ésta tendencia se proyecta en el futuro con consecuentes limitaciones en el progreso económico y social. Ron Knapp (2001), señaló que al año 2000 el promedio de la eficiencia de las carboeléctricas se ubica entre los 30 y 36\%; ahora es aún baja si se compara con la tecnología de gas natural a base del ciclo combinado que es del $57 \%$.

El lento desarrollo tecnológico de las carboeléctricas se aprecia históricamente. De acuerdo con Luque (2002), en los países de Europa hacia 1952, la eficiencia de las carboeléctricas era cuando más de $30 \%$, en 2002 la más alta de $45 \%$ y se proyecta para el 2020 un máximo de 52\% (Figura 6). Bajo estas condiciones, hacia el 2100 se llegaría a alcanzar un $60 \%$ de eficiencia, pero su nivel de emisión de $\mathrm{CO}_{2}$ sería nocivo y aún alto con $0.578 \mathrm{kgCO}_{2} / \mathrm{kWh}$. 


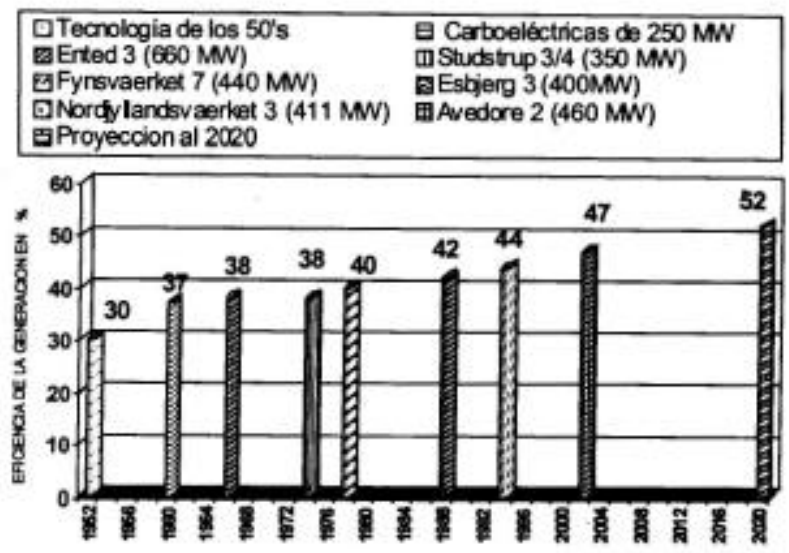

Figura 6. Evolución tecnológica de las carboelectricas en la Unión Europea de 1952 al 2001, y su proyección al 2020

(Elaboración propia con datos de Luque Cabal. 2002)

En síntesis, por su capacidad de generación, la tecnología de menor eficiencia es la del carbón mineral de 23 a 32\%, comparadas con las de más desempeño que son las turbinas de gas de 20 a 34\%, seguidas de las de aceite diésel de 32 a $40 \%$ y la del ciclo combinado a base de gas de 50 a 57\%, y aún más eficientes son las pilas de combustible con base al hidrógeno de 50 a 70\% (AENE 2001). En consecuencia, el término "tecnologías del uso limpio del carbón" que se empezó a utilizar en los 80 's para describir una nueva generación de tecnologias avanzadas de producción de electricidad, a partir del carbón mineral, y que aún se sigue aplicando, es un "augurio prometedor que en la práctica no tuvo efecto." (González, 2002).

\section{Comparación de costos de generación por tecnología empleada}

En los Estados Unidos, las termoeléctricas con base en la energía nuclear y carbón mineral promedian desde hace varias décadas costos de generación (operación, mantenimiento y combustible) menores al de las que utilizan el petróleo y el gas como combustible, de estas cuatro tecnologias a partir de 1999, la nuclear es la de menor costo (NEI, 2001). En efecto, al 2001 los costos de generación con base al gas eran de unos 5.69 CUS/kWh, las de petróleo de 5.28 CUS/kWh, carbón de 1.79 CuS/kWh y nuclear de 1.76 CUS/kWh, siendo la energía nuclear la más competitiva, después de las grandes hidroeléctricas con costo de 1.2
CUS/kWh (NEI, 2003a).

Actualmente, los costos de inversión típicos en plantas nucleoeléctricas nuevas, se encuentran entre los 10001400 \$US/Kw instalado (NEI, 2003c; WNA, 2003). Dicho valor es aún alto al contrastarlo con los 500-600 \$US $/ \mathrm{kW}$ que requieren las de ciclo combinado a base de gas. En consecuencia, para promover la inversión en plantas nucleoeléctricas nuevas, el gobierno de los Estados Unidos apoya su financiamiento hasta en un 50\%.

Adicionalmente, los costos de generación de las plantas nucleares de reciente instalación han tenido un rápido descenso, de 1996 al 2003 pasaron de los 7.1 CUS $/ \mathrm{kWh}$ a un 3.3 CUS/kWh. Se proyecta que hacia el 2010 los reactores de III + generación tendrán costos entre 1.6 a 3.5 CUS/kWh. Entre tanto, hacia el 2015, los de IV generación entrarán al mercado con costos por debajo de los 3 CUS/kWh. Esto se ilustra en la figura 7, donde se comparan el costo de generación de algunos modelos de plantas de III, III+ y IV generación y se observa la tendencia del decremento de sus costos. El Pebble Bed Modular Reactor (PBMR) es el de menor costo (1.5 a 1.7 CUS $/ \mathrm{kWh}$. Con base a estos resultados, para el caso de México, el PBMR podría ser una alternativa tecnológica de generación, de electricidad a corto plazo, debido a su bajo costo de generación, alta seguridad, simplicidad de construcción mediante módulos, $\mathrm{y}$ reducido tiempo de construcción (24 meses). 

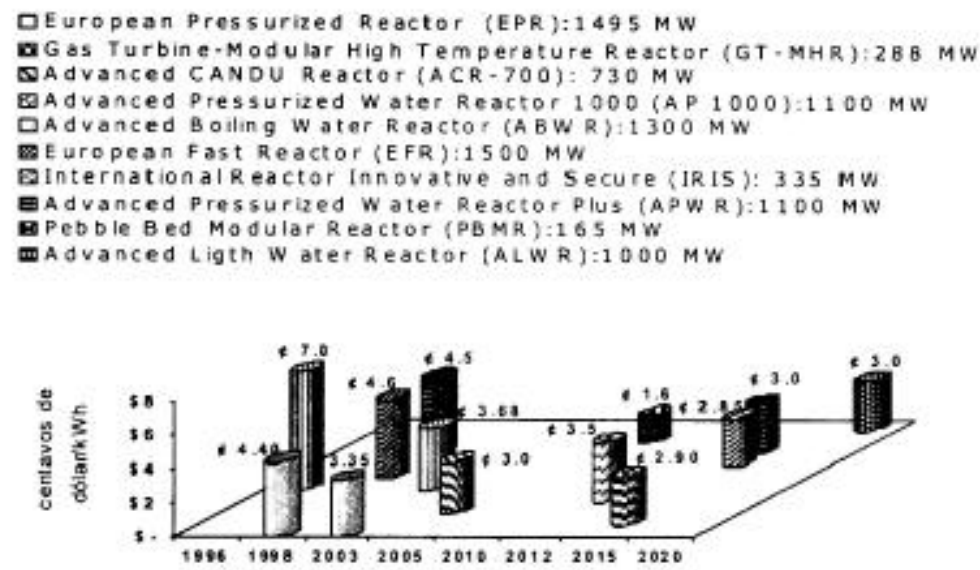

Figura 7. Costos de generación de reactores nucleares nuevos, de 1996 al 2003 y su proyeccion al 2020 (Elaboracion propia con base a 6 referencias

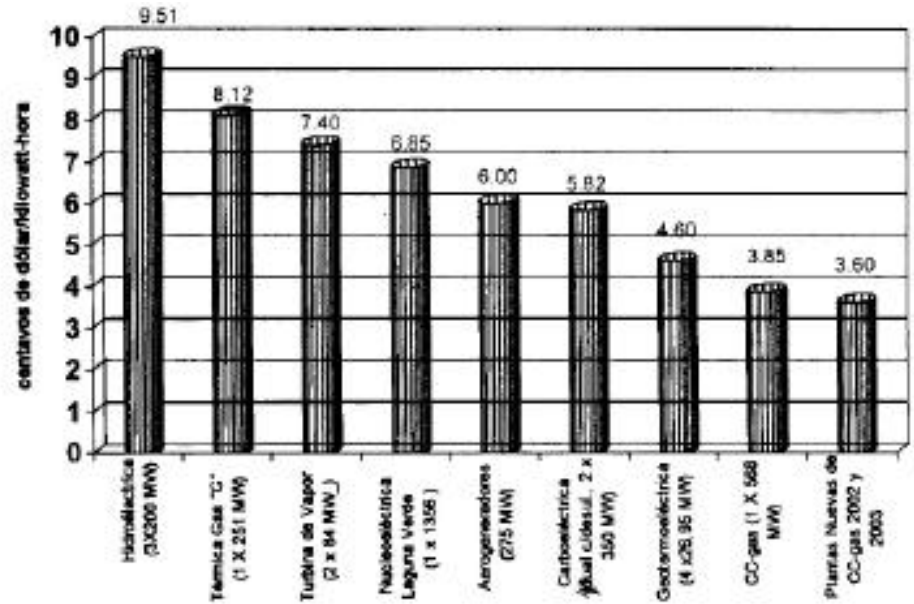

Figura 8. Costos de generación de electricidad en México, al 2003 (Elaboración propia con datos de COPAR, 2003 y SENER, 2003)

En suma, al 2003, los costos totales nivelados de las plantas nucleoeléctricas de III generación estarían entre los $3.2 \mathrm{y}$ 3.7 CUS/kWh; en México estos cóstos son equiparables a los de las nuevas plantas de ciclo combinado a base de gas, del orden de 2.5 y $3.6 \quad$ CUS $/ \mathrm{kWh}$ (figuras 7 y 8 ). Además, la viabilidad económica de las nucleoeléctricas se favorece por su mayor factor de planta,

alcanzan un 92\%, mientras que las de ciclo combinado son de $80 \%$. En estas condiciones, por ejemplo, si ambas tecnologias participaran con costos similares, la de mayor factor de planta sería la más viable, es decir, la nucleoeléctrica.

Al contrario de lo que acontece con otras tecnologías, la viabilidad de las termoeléctricas que emplean el gas como combustible son muy sensibles a los cambios del precio de su combustible, al representar el $70 \%$ del total (NEI, 2002). Entre tanto, según GE (2000), para el caso de las nucleoeléctricas, los costos de inversión representan el 70\%, operación y mantenimiento el $15 \%$ y los combustible un 15\%. Para los reactores de neutrones rápidos, el costo del combustible es de menos del 1\% (Cohen Bernard, 2002). Por todo lo anterior, en las plantas nucleoeléctricas una fuerte alza del precio de su combustible tendría menor impacto. Entre tanto, en los mercados con precios ascendentes de gas natural, como ocurre 


\section{S.D. Bazán-Perkins}

recientemente en Estados Unidos, México, Brasil, Argentina y otros países, las plantas de ciclo combinado a base de gas pierden competitividad.

El primer reactor de III generación comercial Advanced Boiling Water Reactor (ABWR) se construyó en tapón, inició su operación en 1996 con costos de unos 7.1 CUS/kWh, hacia el 2003, se situó en 3.68 CUS/kWh (WNA, 2003). En general, el decremento de los costos de generación de las plantas nucleoeléctricas se favorece en aquellos países que compensan los altos costos de su inversión mediante depreciación acelerada (GE, 2000). Así, en los Estados Unidos sus centrales nucleoeléctricas, la mayoría construidas en los 70's, promediaron para el 2001 costos de 1.76 CUS/kWh (NEI, 2003a). Recientemente, los Estados Unidos para impulsar las inversiones en nuevas plantas nucleoeléctricas otorga una depreciación más acelerada, al pasar de los 15 a 7 años.

\section{Efectos nocivos al ambiente}

Efectos a la salud y al ambiente de las fuentes de generación de electricidad

La electricidad, que es un servicio básico para mejorar la calidad de vida del ser humano, en su proceso de generación, provoca una serie de trastornos negativos al ambiente y a la salud hut mana; tales como: enfermedades, accidentes, reubicación de asentamientos humanos, muertes prematuras y daños a los ecosistemas, al suelo, al agua $\mathrm{y}$ al aire. Todo esto, debido al calentamiento global, adelgazamiento de la capa de ozono, acidificación, intrusión visual, deforestación, degradación de las aguas, cenizas, radiaciones ionizantes, residuos industriales y radiactivos, contaminación por metales pesados, sustancias carcinógenos y niebla tóxica (COP 6 bis, 2001; APPA, 2002). Antes, se desconocía el efecto y el costo total de estas afectaciones, desde la prospección del recurso energético hasta la generación de electricidad, cierre, desmantelamiento y saneamiento de la planta.

A mediados del 2001, a partir de once años de investigación en 15 países de la Comunidad Europea y los Estados Unidos, se publicaron los resultados obtenidos del Proyecto Externe EE.UU.CE (2000-2001), que definen por primera vez los costos de las externalidades de las tecnologias de generación de electricidad. Los resultados generales determinan altos costos ambientales para las tecnologias del carbón mineral, eólica y petróleo (Figura 9).

Sin este criterio, casi todos los proyectos de generación de electricidad altamente nocivos al ambiente se aprueban como viables. Se contempla que en el futuro, cada país se le responsabilizará con un costo a sus productos, de las consecuencias negativas de su política energética, que atenta contra la salud de la población mundial. En efecto, los aspectos ambientales son un factor determinante en la elección de las fuentes de energía de cada país, repercute en las relaciones

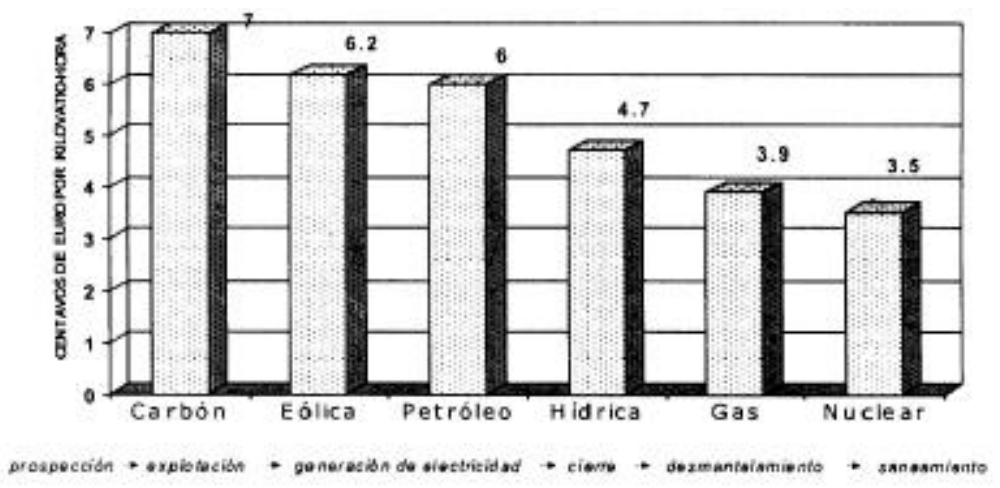

Figura 9. Proyecto Externe EE.UU.- CE, 2000-2001. Costo de las externalidades de la generacion de electricidad por tecnologia empleada (Elaboración propia con datos de COPO, 2001) ce/kWh 
bilaterales y conlleva en algunos casos a requerir la modificación o descalificar proyectos de infraestructura energética de otras naciones, a fin de aminorar las afectaciones de sus plantas generadoras de electricidad en solidari dad.

En el caso de México, las carboeléctricas del Noreste del país al 2003 se encontraban entre las de menor costo de generación (Figura 8). Sin embargo, sus sistemas anticontaminantes son insuficientes; según Rincón y Emerson (2000) y Sage (2000) contribuyen en la formación de la neblina tóxica que afecta a las cuencas atmosféricas de Big Bend, Sunland Park, El Paso y Ciudad Juárez, con las consecuentes secuelas de reclamos ambientales de Estados Unidos hacia México. Las Naciones Unidas (ONU, 1998), proponen desvincular los beneficios económicos por no cumplir con las normas ambientales adecuadas en los países en desarrollo, mediante impuestos ambientales y transferencia de tecnologias ecológicamente racionales. En este sentido, la experiencia obtenida señala que mediante asociaciones comerciales se obtienen espectaculares incrementos de capacidad de tecnologia sustentable en los países en desarrollo.

Actualmente, las normas ambientales en Estados Unidos, por arriba de las normas internacionales, han detenido la explotación de los grandes campos de gas natural ubicadas en las regiones federales (Refugio Nacional Ártica, De Fauna en Colorado, Utah, Nuevo México y Golfo de
México). También ha restringido la autorización de obras civiles para el almacenamiento de gas licuado en puertos, por su alta peligrosidad (Greenspan, 2003 a y b).

A su vez, el programa de Energía Atómica 2010 de Estados Unidos, favorece la construcción de nuevas plantas nucleares hacia las regiones más contaminadas de este país, a fin de mejorar sus condiciones ambientales (NEI 2003a). El estado de California es el más gravemente contaminado y con altas necesidades para que se incremente la generación eléctrica de cero emisiones, como sería la energía nuclear y las renovables, en sustitución de las termoeléctricas a base de combustibles fósiles (Figuras 9, 10, 11 y tabla 1).

Las plantas nucleares, además de no generar gases de efecto invernadero, las áreas en su entorno se convierten en zonas de preservación ecológica mucho más controlada y continuamente mejorada. Han restituido la calidad del agua de su entorno contaminado por otras industrias, propician nuevas zonas de recreación y de ecoturismo, evitan el tráfico de especies y las actividades que provocan disturbios ecológicos, participan en estudios técnicos y culturales, y ayudan a reintroducir especies extintas en la región o en vías de extinción (NEI, 2002c).

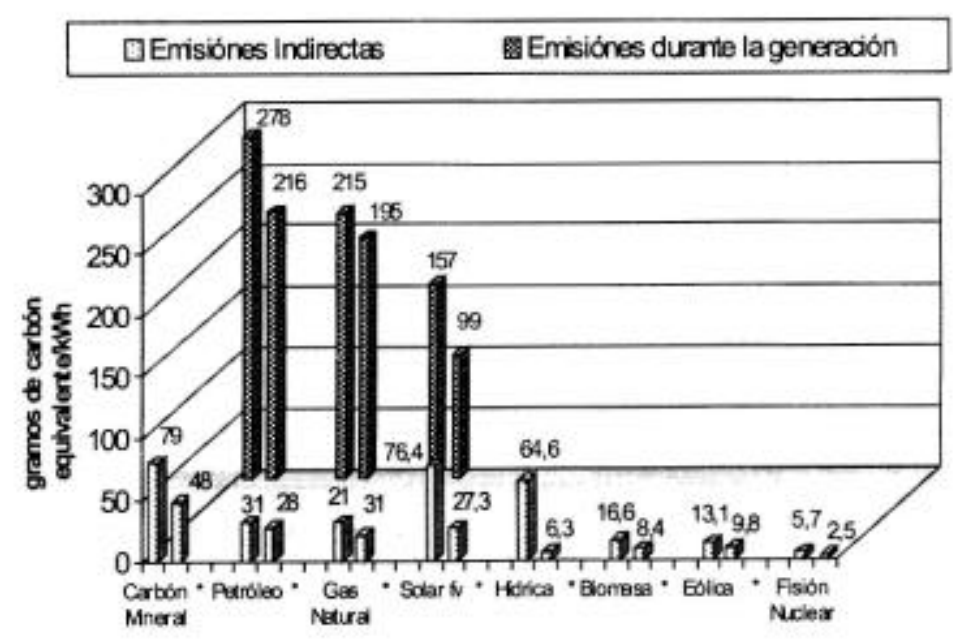

Figura 10. Emisiones de gases de Efecto Invernadero por tecnología empleada en la generación elétrica al 2000, rangos de variación (Elaboración propia con datos de Spadaro et al. 2000) 


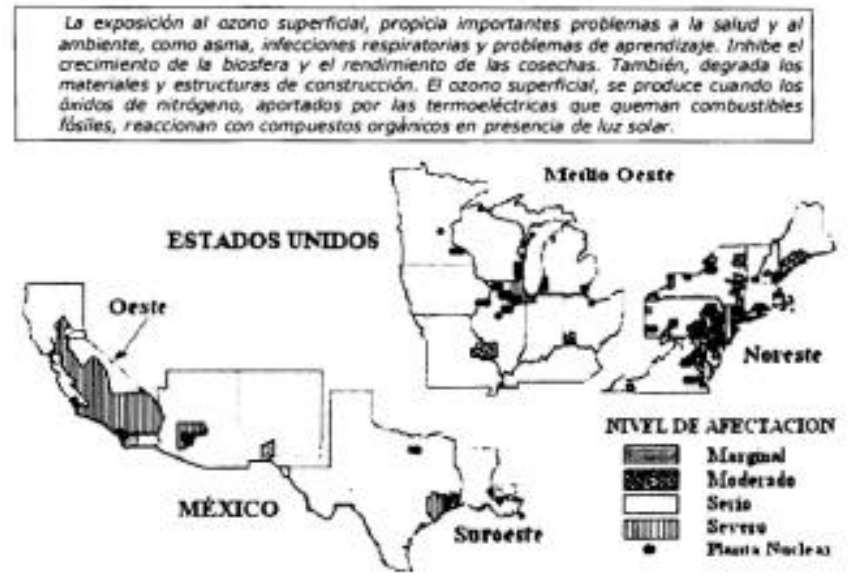

Figura 11 El programa de energia atómica 2010 de los Estados Unidos ayudara al decremento de la contaminación del aire por ozono. la región Oeste requiere un mayor nümero de plantas nucieoeléctricas (Adaptado de NEI. 2003a)

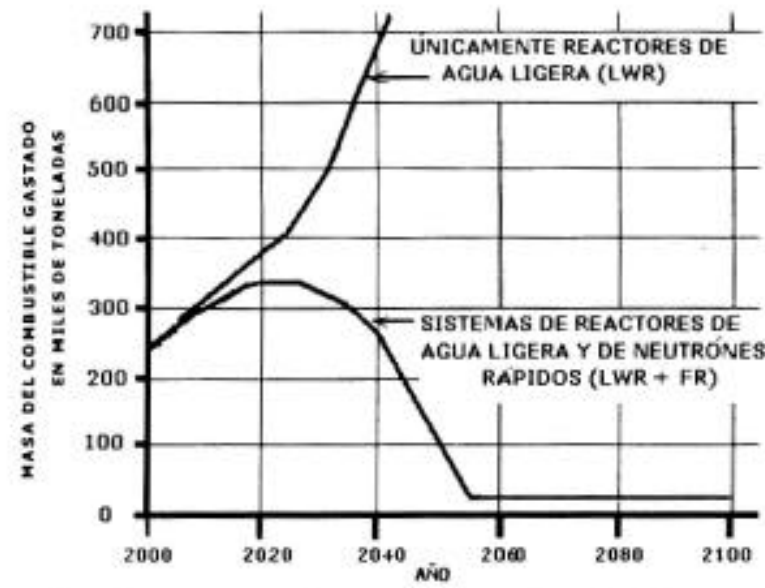

Figura 12. Decremento del combustible nuclear gastado. almacenado en el mundo al integar sistemas de reactores rápidos y de agua ligera, proyección al 2100 (Adaptado de DOE, 2002)

\section{Disposición de los desechos radiactivos}

La mayoría de los países que cuentan con plantas nucleoeléctricas, ocupan los combustibles nucleares una vez para su posterior almacenamiento en cilindros de acero, cerca de las plantas, como es el caso de los Estados Unidos y México. Otros países como Francia, Inglaterra, Suiza y Japón, recuperan y procesan el uranio y el plutonio de los combustibles gastados, lo utilizan para hacer nuevo combustible y transmutan los inaprovechables a otros de menor vida de toxicidad, reduciendo de esta forma el almacenamiento.

En el futuro se pretende obtener un costo bajo en el procesamiento de los combustibles gastados y contar con un mayor número de reactores de neutrones rápidos en el mercado. En consecuencia, al intensificar estas dos líneas de desarrollo se modificaría radicalmente el paradigma de la generación de energía. Al decrementar en gran medida, tanto la explotación de las materias energéticas primarias mundiales (carbón, petróleo, gas, uranio y biomasa) como los inventarios de los combustibles nucleares gastados.

En este sentido, los reactores nucleares de IV generación que entrarán al mercado del 2015 al 2025, incluyen en tres de sus seis modelos básicos, reactores comerciales de neutrones rápidos (fast 
reactor), diseñados para consumir el plutonio y uranio agotado y transmutar los tóxicos, producido por otras centrales nucleares. De esta forma, se pretende resolver la principal preocupación del empleo de la generación nuclear concerniente a la proliferación y al volumen de residuos que esta industria produce (DOE, 2002b y 2003), (Figura 12).

\section{Conclusiones y recomendaciones (Primera Parte)}

1. Del conjunto de oportunidades de generación de electricidad disponibles en México, las basadas en la energía nuclear en conjunción con las renovables, podría ser la opción más viable; conforme a los nuevos avances tecnológicos y de mercado de los energéticos analizados en perspectiva global y nacional. Su desarrollo en el país requiere de un cambio radical en la forma de pensar, un reto para asumir tecnologías más avanzadas que requieren de miles de profesionistas $\mathrm{y}$ técnicos calificados en todas las áreas. Representa en sintesis, la mejor forma de impulsar un gran número de actividades tecnológicas, de mercado, comercial, bursátil y desarrollo de centros de investigación en el país.

2. El emplazamiento del desarrollo de la energía nuclear repercute en México en el limitado y lento desarrollo de las fuentes de energía renovables. Se trata de una estrategia porque al integrarlas, se compensan los altos costos de las renovables con los bajos costos de la nuclear. Con ambas tecnologías se podrian producir combustibles avanzados para el transporte vehicular, el hidrogeno y la biogasolina. En sí, por su alto factor de disponibilidad, la energía nuclear puede respaldar a las renovables dependientes de la climatología y producir agua potable comercial para el sector doméstico, agrícola e industrial.

3. Por consecuencia, la tecnología nuclear en conjunción con las renovables podría cubrir la demanda de electricidad en México en forma eficiente $y$ producir excedentes para su exportación en forma masiva y competitiva, como fuente importante de ingresos del país. Lo anterior sé logra mediante acuerdos bilaterales con Estados Unidos y Centro América para suplir la energía eléctrica generada por procesos contaminantes en la región fronteriza, por la generación limpia. En consecuencia, la oportunidad que tiene México de convertirse en gran abastecedor de electricidad, agua potable e hidrogeno al estado de California, sería mediante el desarrollo de la energía nuclear.

4. La actual política energética, apostada en el gas natural para generar electricidad, está en el umbral de la inviabilidad. Esto se debe a la volatilidad y alto precio del gas natural en el mercado, que cada vez supera más los 5.00 \$US/millón de Btu, a partir de la cual las plantas de ciclo combinado pierden competitividad, según Herman et al. (2001). También por las bajas reservas domésticas de gas natural $y$ petróleo, incluyendo sus afectaciones ambientales que provocan en la producción de electricidad.

5. Es necesario, por tanto, iniciar a corto plazo en México un programa para la construcción de centrales nucleares de III + y IV generación, cuyos primeros modelos entrarán en operación comercial hacia el 2010 y 2015, respectivamente. Este plan sería transformar la actual economía petrolizada a una economía del hidrógeno hacia el 2030, básicamente en sustitución de los actuales combustibles por el hidrógeno para el transporte automovilístico. Ahora, la ventaja será que México puede empezar con tecnología de punta, lo que significa un gran ahorro económico y tiempo; el mercado tiene a disposición modulares reactores de diseño avanzado para construir a seis años; en donde dos son de planificación y cuatro años de obra de construcción, para 60 años de operación en condiciones de inversión competitiva. De estos nuevos desarrollos el Pebble Bed Modular Reactor (PBMR) con un costo de $1.6 \mathbf{C}$ US/kWh podría ser la mejor opción tecnológica para México.

6. Con base en la experiencia internacional, el carbón mineral para la generación de electricidad, implica bajo progreso económico con mayor daño al ambiente y a la salud humana. Se trata de una tecnología deficiente y de evolu- 
ción lenta que no promueve mayor desarrollo tecnológico, en comparación con otras tecnologías de generación de electricidad. La internacionalización de los costos ambientales (externalidades) implica que al intensificar su empleo se incrementará el arancel por las afectaciones que genera $y$ al mismo tiempo se le resta al país la oportunidad de exportar un flujo de electricidad limpia. Su excesivo empleo trasciende las fron teras e influye a nivel planetario en el efecto invernadero y consecuente cambio climático;-como lo son ya los reclamos fronterizos de los Estados Unidos a México por supuestas afectaciones ambientales de las carboeléctricas del noreste del país, en la región de Big Bend,Texas.

7. Finalmente, las altas inversiones que requiere la etapa de construcción de centrales nucleares e hidroeléctricas, podrán ser administradas por el estado, a partir de un financiamiento de emisiones para ser ofrecidas en el mercado.

\section{Referencias (Primera Parte)}

AENE (2001). Generación distribuida, más económico, más limpio, más seguro. Jornadas Internacionales de Energía Eléctrica, Octubre, Colombia.

APPA (2002). Impactos ambientales de la producción de electricidad. Análisis de ciclo de vida de ocho tecnologías de generación eléctrica. Asociación de Productores de Energias Renovables, España.

Bardwell S. (1981). El modelo econométrico la Rouche-Riemann. Revista bimestral Fusión, Vol. 1, No. 1, Enero, USA, pp. 42-55, ISSNO272-1147.

Bateman A.M. (1982). Yacimientos minerales de rendimiento económico. Editorial Omega, Sexta Edición, pp. 75.

BP (2001 , 2002 y 2003 ). Statical Review of World Energy, 1965 to 2000, 1965 to 2001, 1965 to 2002.

Brundtland G.H. (1987). Our Common Future: From One Earth to One World. Oxford University Press, New York.

CFE (2002). CFE: Retos 2002-2011, hacia una empresa de clase mundial, México.

CNEA (2002). La politica nuclear argentina Atucha II, Argentina.

Cohen B. L. (1983). Breeder Reactors: Arenewable Energy Source. American
Journal of Physics, Vol. 51, (1).

COP 6 bis (2001). La energía nuclear en la cumbre del cambio climático. Foro Nuclear, España, pp. 17.

COPAR (2003). De generación, cuadro A. 1, Gobierno pp. 21. México.

Diario del Pueblo (2000). Viraje favorable en las ramas clave de la economía, 2000, 3, Agosto, 1 de Enero del 2001, 10:32(Gmt+8), China.

Diario del Pueblo (2001 a, 2001 b). Economía China crece ocho por ciento el año 2000 y China establece récord de exportación de Carbón, 1/Enero/2001, 10:32(Gmt+8), 10:32 (Gmt+8), China.

DOE (2002a). A National Vision of America's Transition To a Hydrogen Economy. Department of Energy US, pp. 27.

DOE (2002b). A Technology Roadmap for Generation IV Nuclear Energy Systems. Committee and the Generation IV International Forum, GIF-002-00, Department of Energy US.

DOE (2003). Report to Congress on: Advanced Fuel Cycle Initiative: "The Future Path for Advances Spent. Department of Energy US, pp. 45.

Dunbar C.O. (1980). Geología histórica. Editorial Continental, México, pp. 556.

Echavarri L.E. (2002). Nuclear Energy and Sustainable Development in the OECD. Nuclear Energy Agency, DirectorGeneral, Winter Seminar, 19 February, 2002.

Eurobser (2003). Wind Energy Barometer. Le Barométre de L' "eolien, pp. 13.

FernándezZayas J.L. (2003). Posibilidades actuales del hidrógeno como energético en México. Director General de Investigación y Desarrollo, SENER, México.

FRAMATOME-ANP (2003). Reactors Models: The CNP-1000 Reactor, The European EPR Reactor, SWR 1000 Model. The Magazine of Framatome ANP, France.

GE (2000). Advanced Boiling Water Reactor Plant General Description, First of the Next Generation General Electric Company.

Gerber C.R., Hamburger R. y Seabrook H.E.W. (1966). Plowshare. Comision de Energía Atómica de los Estados Unidos, USA, pp. 58.

González-Blas J. (2002). Uso limpio del carbón. Jornada sobre tecnologías de uso limpio del carbón, España. 
Greenspan A. $(2003$ b). Natural Gas Shortage Could Hurt Economy, Washington. Artículo por Joseph Guinto, Web Jun 1 1, 10:16 AM ET, Yahoo News, sun, Jun 15.

Greenspan A. (2003a). Testimony of Chairman Alan Greenspan Natural Gas Supply Before the Committee on Energy and Natural Resources, July, 10, USA.

Gutín I.J.M. (2001). El futuro eólico ya está aquí. CIEMAT, 30 de Agosto del 2001, España.

Gutín I.J.M. (2002). Otro paso adelante en la generación eólica. CIEMAT, España.

Herman J.A.A., Lowe J.J. and Schoff R.L. (2001). The Economics of Gas Turbines in the PJM Region. Department of Energy, National Energy Technology Laboratory, USA, pp. 135.

IAEA (2002). Latest News Related to Pris and the Status of Nuclear Power Plants. Power Reactor Information System (PRIS).

IEA (2002). Key World Energy Statistics. International Energy Agency, France.

Infoenergía (200 la). Dewind instala y desarrolla nuevos modelos. CIEMAT, España.

Infoenergía (2002b). La última en llegar: G80-1500 kW, CIEMAT, publicado el 4 de Junio del 2002, España.

IPHE (2003). International Partnership for the Hydrogen Economy Ministerial Meeting, http://www.usea.org/iphe2.htm Laherrere J.H. (2003). Forecast of Oil and Gas Supply 2050, Hydrocarbons Resources, New Delhi, January 9.

Luque C.V. (2002). El papel de las tecnologías limpias del carbón en el contexto de la seguridad del aprovisionamiento en Europa. Jornada sobre tecnologías de uso limpio del carbón, España.

NE (2003). Nuclear Hydrogen Initiative. Office of Nuclear Energy, Science and Technology US Department of Energy, March, 2 páginas, USA, Web: nuclear.gov NEI (2001). Nuclear Energy Surpasses Coal-Fired Plants as Leader in Low Cost Electricity Production. Nuclear Energy Institute, USA.

NEI (2002c). The Outlook for Nuclear Energy in a Competitive Electricity

Business, Reliable,
Economical Energy. Nuclear Energy Institute, Washington, DC, USA.

NEI (2003 a). Nuclear Energy and The Nation's Future Prosperity, Vision 2020. Nuclear Energy Institute, pp. 23, USA.

NEI (2003b). Powering Tomorrow..., With Clean,' Safe Energy, Vision 2020. Nuclear Energy Institute, pp. 24, USA.

NEI (2003c). CBO Report Draws Faulty Conclusions in Cost Analysis of New Nuclear Plants. Nuclear Energy Institute, USA.

ONU (1998). Conferencia de las Naciones Unidas Sobre Comercio y Desarrollo, TD/B/Com.1/EM.7/2, pp. 32.

Rashad S.M. y Hammad F.H (2000). Nuclear Power and the Environment Comparative Assessment of Environmental and Health Impacts of Electricity-Generating Systems. Applied Energy, V. 65, Issues 14, April 2000, pp. 21 1-229.

REW (2002a). Another Record Year for European Wind Power, Rew News, Renewable Energy Woorl, March-April, 2002, London.

REW (2002b). Serios Megawatts, The US Taps into Wind's Enormous Potential, Rew News, Renewable Energy Woorl; March-April, 2002, London.

Rincón C. y Emerson P. (2000). La gestión binacional de la calidad del aire en la zona fronteriza entre EE.UU. y México. Revista Borderlines, Vol.8, No. 1, enero, USA.

Knapp R. (2001). Coal Technology for the Future-Reducing the Environmental Footprint. Word Coai Institute, 24-25 September' 2001 , pp. 12.

Ruiz V.V. y Garre C.I.A. (2000). Normalización en el campo de la energía eólica CIEMAT, España.

Sage F.K. (2000). La problemática actual en torno a la contaminación del aire en Big Bend, Texas. Revista Borderlines, Vol, 8, No. 1, enero, USA.

SENER (2002 y 2003). Prospectiva del Sector Eléctrico 2002-201 1 y 2003-2012. Secretaría de Energía, México.

Spadaro I.V., Langlois-Lucille y Hamilton Bruce (2000). Greenhouse Gas Emissions of Electricity Generation Chains, International Atomic Energy Agency. Bulletin 42, No. 2, pp. 6.

Suárez C.J.J. (2003). Padece declive cantarell, economía y finanzas. Periódico Reforma reportaje de Shields David, 20 Enero del 2003, PEMEX, México. 
U.S. Government (2001). Report of the National Energy Policy Development Group, Seal of President of The United States.

U.S. Government (2003). Nuclear Energy Program and Buget Details/Office of Nuclear Energy, Science and Technology, Energy Independence Initiative, President's Budget FY 2004.
Uranium (2000 y 2001). Ressources, Production et Demande, OECD. Agence Internationale de I'Energie Atomique.

WNA (2000). A Weekly Summary of International News Relevant to the Nuclear Energy Industry. World Nuclear Association, 31 May - 6 June 2000.

WNA (2003). Energy for Sustainable Development, Advanced Reactors. World Nuclear Association, September 2003.

Semblanza del autor

Sergio D. Bazán-Perkins. Realizó la licenciatura en ingeniería geológica en la Facultad de ingeniería de la UNAM, con mención especial. Obtuvo el grado de maestro en ingeniería en investigación de operaciones, orientada a las finanzas en la Facultad de ingeniería de la UNAM y en donde actualmente cursa el doctorado en el campo de la economía de la energía. Es autor de 45 trabajos publicados en revistas y congresos nacionales e internacionales con arbitraje. Ha ocupado diversos puestos directivos y de supervisión en entidades gubernamentales y privadas. 